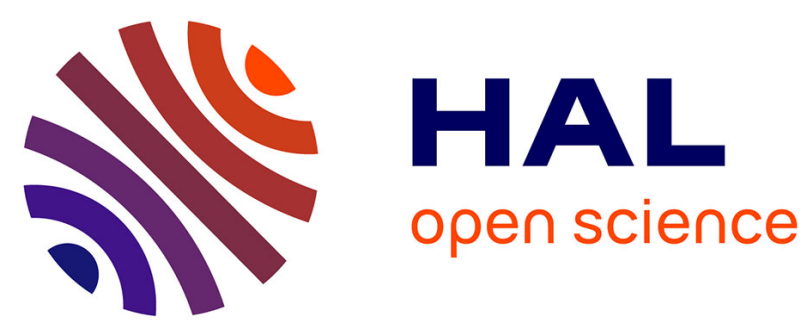

\title{
Embryonic zeolites for highly efficient synthesis of dimethyl ether from syngas
}

Ana Palčić, Sara Navarro Jaén, Dan Wu, Mengdie Cai, Chong Liu, Evgeny A Pidko, Andrei Khodakov, Vitaly Ordomsky, Valentin Valtchev

\section{- To cite this version:}

Ana Palčić, Sara Navarro Jaén, Dan Wu, Mengdie Cai, Chong Liu, et al.. Embryonic zeolites for highly efficient synthesis of dimethyl ether from syngas. Microporous and Mesoporous Materials, 2021, 322, pp.111138. 10.1016/j.micromeso.2021.111138 . hal-03424400

\section{HAL Id: hal-03424400 https://hal.science/hal-03424400}

Submitted on 18 Nov 2021

HAL is a multi-disciplinary open access archive for the deposit and dissemination of scientific research documents, whether they are published or not. The documents may come from teaching and research institutions in France or abroad, or from public or private research centers.
L'archive ouverte pluridisciplinaire HAL, est destinée au dépôt et à la diffusion de documents scientifiques de niveau recherche, publiés ou non, émanant des établissements d'enseignement et de recherche français ou étrangers, des laboratoires publics ou privés. 


\section{Embryonic zeolites for highly efficient synthesis of dimethyl}

\section{ether from syngas}

Ana Palčićc ${ }^{a}$, Sara N. Jaen ${ }^{b}$, Dan Wu, Mengdie Cai ${ }^{b}$, Chong Liuc ${ }^{c}$, Evgeny A. Pidko ${ }^{c}$, Andrei

Khodakov $^{b}$, Vitaly Ordomsky ${ }^{b}$, Valentin Valtchev ${ }^{d *}$

${ }^{a}$ Ruđer Bošković Institute, Division of Materials Chemistry, Laboratory for Synthesis of New Materials, Bijenička cesta 54, Zagreb, Croatia

${ }^{b}$ Univ. Lille, CNRS, Centrale Lille, Univ. Artois, UMR 8181 - UCCS - Unité de Catalyse et Chimie du Solide, F-59000 Lille, France

${ }^{c}$ Inorganic Systems Engineering, Department of Chemical Engineering, Delft University of Technology, Van der Maasweg 9, 2629 HZ Delft, The Netherlands

${ }^{d}$ Normandie Univ, ENSICAEN, UNICAEN, CNRS, Laboratoire Catalyse et Spectrochimie, 6 Boulevard Maréchal Juin, Caen, France 
ABSTRACT. Embryonic X-ray amorphous semi-formed MFI-type units mixed with Cu-Zn-Al has been used for the direct synthesis of dimethyl ether (DME) from syngas. The embryonic zeolite (EZ) has demonstrated superior performance in terms of activity, selectivity, and stability compared to the crystalline ZSM-5 counterpart and an amorphous aluminosilicate with similar composition. The particle size of the embryonic zeolite is about $5 \mathrm{~nm}$. Several types of active sites are present in the EZ, including medium strength Brönsted acid sites, as revealed by the FTIR pyridine adsorption. The DFT modeling pointed outthe key role of defect sites leading to lower strength of the acid sites in the embryonic MFI zeolite in comparison with the fully crystalline zeolite. The effect of embryonic zeolite on DME synthesis has been assigned to enhanced transport of methanol from $\mathrm{Cu}$ to ultra-small zeolite precursor units with medium acidity, providing efficient dehydration to DME with high selectivity and stability.

KEYWORDS: Embryonic zeolite; acid sites; DME synthesis; syngas. 


\section{Introduction}

Zeolites are crystalline microporous materials with the tetrahedron as the essential constituent of their structure. A tetrahedron comprises central $\mathrm{T}$ atom $(\mathrm{T}=\mathrm{Si}, \mathrm{Al}, \mathrm{Ge}, \mathrm{Ga}, \mathrm{P}$, $\mathrm{B}, \ldots)$ and oxygen at vertices, and upon getting connected by sharing the oxygen atoms, a threedimensional system of voids and channels is formed. The attribute microporous signifies that the framework voids (cages, channels, pore openings) are smaller than $2 \mathrm{~nm}$. Zeolites represent the the largest class of solid acid catalysts that are employed in numerous commercial processes such as oil refining and fine chemicals production as well as exhaust gas treatmentRef. Theyare also utilized in detergents, water treatment, radionuclide removal, air purification, gas separation, odor removal, plastic additives, agriculture, etc. [1]. The diverse applications of zeolites stem from their properties - porosity, high surface area, acidity/basicity, ion-exchange capacity, controlled hydrophobicity/hydrophilicity that originate from their framework array and chemical composition [2]. The presence of acid sites at defined positions together with the unique micropore topology, governs the usage of zeolites as catalysts that may present reactant, transition state, product, or shape selectivity. However, due to the rigid framework and welldefined size of the pores, the maximal size of the molecule that can enter the pores is close to or smaller than the pore dimensions. Furthermore, in conjunction with the size and morphology of the crystals, mass transport constraints on both,reactants and products, may ensue [3]. Hence, the access to the active sites in the intracrystalline voids is often restricted, and the reaction mostly takes place at the active sites situated or close to the external surface of the crystals. The strategies to suppress the diffusion limitation and thus improve catalyst effectiveness and total performance involve reducing the size of the crystals $[4,5,6]$ and preparing crystals with larger voids, usually mesopores [7,8,9] but also extra-large pore zeolites [10].. Continuous research 
efforts have been devoted to discovering extra-large pore zeolites during the last two decades. However, there is still not a zeolitic material that could face the requirements of chemical and (hydro)thermal stability, chemical reactivity, and affordable production conditions. Recently was proposed a new route in overcoming the mass transfer limitations in the zeolites by decreasing their size to the unit cell dimension[11]. These materials are ultra-small (3-5 nm) X-ray amorphous zeolitic units [12]. Their properties and catalytic performance in bulky molecules conversion expand the opportunities of the utilization of already existing crystalline zeolites [13]. Recently, a substantial advance in the control of porosity, acidity, and substrate molecules accessibility of the embryonic zeolites was achieved, which opened the route for some new catalytic applications [14]. Namely, materials having extra-large pores (1-2 nm) and a low quantity of acid sites of moderate strength were prepared. These embryonic zeolites are highly active catalysts in the dealkylation of bulky 1,3,5-triisopropylbenzene. Hence, herein is proposed the application of embryonic zeolites from MFI-type zeolite yielding system as a catalyst for DME synthesis from syngas.

Dimethyl ether (DME) is the simplest ether and nowadays, it is considered an alternative to conventional fossil fuel resources [15]. It is an important intermediate for synthesizing different chemicals [16]. It can be regarded as an alternative technology to Fischer-Tropsch transformation of syngas produced from biomass as a renewable resource. The DME is produced in two steps with $\mathrm{CO}$ hydrogenation to methanol over a copper-based catalyst and subsequent dehydration to DME over acid catalysts [17], yet the methanol yield is low due to the thermodynamic limitation, which makes the product expensive [18]. In the direct DME synthesis from syngas the thermodynamic equilibrium is shifted to the target product $[19,20]$. It results in 
a significant increase in the conversion of $\mathrm{CO}$ and higher DME productivities, but the presence of water and $\mathrm{CO}$ in the reactor leads to water gas shift reaction: $\mathrm{CO}+\mathrm{H}_{2} \mathrm{O}=\mathrm{CO}_{2}+\mathrm{H}_{2}$.

The direct synthesis of DME requires bifunctional hybrid catalysts possessing metallic and acidic functions. The most common catalyst for the $\mathrm{CO}$ hydrogenation is $\mathrm{Cu}-\mathrm{Zn}-\mathrm{Al}$ (CZA) prepared by co-precipitation $[21,22,23]$. This material is cheap and contains highly dispersed $\mathrm{Cu}$ nanoparticles stabilized by $\mathrm{ZnO}[19,24]$. Acidic catalyst is needed for dehydration of methanol, and the zeolites have been found to be the most appropriate due to their tunable acidity and high hydrothermal stability $[25,26]$. Traditionally ZSM-5 has been used for DME synthesis [27], yet other zeolite materials (FER, MCM-22, ITQ, SAPO-5, -11 -21) have also been tested for this reaction $[28,29]$.

There are several issues related to the bifunctional catalyst for DME synthesis. Firstly, the activity of the catalyst depends on the close contact between metal and zeolite active sites. Accordingly, a decrease in the size of zeolite particles in the intimate mixing with CZA leads to a significant increase of the catalytic activity due to the fast transfer of methanol from metal function to zeolite [30]. Strong acid sites induce deeper transformation of methanol and generate hydrocarbons, thus decreasing the selectivity to DME. The catalyst deactivation is another important problem during DME synthesis. It has been attributed to copper migration [31] and sintering in the presence of water and acid sites of zeolites [32]. The catalyst deactivation was also associated with the coking [33]. The analysis of the literature data shows that an optimized catalyst of high activity, selectivity and stability for DME synthesis has to include close proximity of metal and acid sites of medium strength. These criteria are fulfilled by the embryonic zeolites and hence their potential as catalysts for DME synthesis was study. 


\section{Experimental section}

\section{Catalyst Preparation}

The $\mathrm{CuO}-\mathrm{ZnO}-\mathrm{Al}_{2} \mathrm{O}_{3}$ catalyst $(\mathrm{Cu}: \mathrm{Zn}: \mathrm{Al}=60: 30: 10$ atomic ratio) was prepared by coprecipitation at constant $\mathrm{pH}(\mathrm{ca} .7)$ at $70{ }^{\circ} \mathrm{C}$. Aqueous solutions of copper(II) nitrate (0.6 M), zinc nitrate $(0.3 \mathrm{M})$ and aluminum nitrate $(0.1 \mathrm{M})$ were mixed at $70{ }^{\circ} \mathrm{C}$. Afterward, a $0.5 \mathrm{M} \mathrm{Na}_{2} \mathrm{CO}_{3}$ solution was added drop by drop. The resulting precipitate was kept under stirring at $70{ }^{\circ} \mathrm{C}$ at a constant $\mathrm{pH}$ of 7 for 1 hour. The precipitate was then filtered, thoroughly washed with distilled water, and dried at $100{ }^{\circ} \mathrm{C}$ overnight. The solid was finally calcined at $350{ }^{\circ} \mathrm{C}$ for 4 hours, at a heating rate of $2{ }^{\circ} \mathrm{C} \cdot \mathrm{min}^{-1}$.

The embryonic zeolite was synthesized using tetrapropylammonium hydroxide (TPAOH, Alfa Aesar, 1M), tetraethoxysilane (TEOS, Aldrich, 98\%), di-secbutoxyaluminoxytriethoxysilane (DSBATES, ABCR GMBH), and doubly distilled water produced in our laboratory. Firstly, the needed amount of TPAOH was mixed with the water in a polypropylene bottle, followed by the addition of DSBATES. Upon $24 \mathrm{~h}$ stirring, TEOS was added to reach, giving a reaction mixture with the following molar composition 25 DSBATES : 9 TPAOH : 127 TEOS : $500 \mathrm{H}_{2} \mathrm{O}$. The solution was stirred for an additional $24 \mathrm{~h}$ and subsequently treated for 10 days at $100{ }^{\circ} \mathrm{C}$ in a convection oven. The recovered solid phase has been washed three times with acetone and then with water until a neutral $\mathrm{pH}$ was attained. $3 \mathrm{~g}$ of the sample was further three times treated with ammonia chloride solution, $\left(\mathrm{c}\left(\mathrm{NH}_{4} \mathrm{Cl}, \mathrm{Alfa}\right.\right.$ Aesar, 98\% $=0.5 \mathrm{M} ; \mathrm{V}($ solution $\left.)=30 \mathrm{~cm}^{3}\right)$, each time for $4 \mathrm{~h}$ at $80{ }^{\circ} \mathrm{C}$. Next, the washed material was calcined for $10 \mathrm{~h}$ at $550{ }^{\circ} \mathrm{C}$, and thus the EMB sample was obtained.

Two types of reference catalysts have been used to evaluate the catalytic properties of embryonic zeolite. First reference catalyst is an amorphous aluminosilicate denotedas $\mathrm{SiO}_{2}-$ 
$\mathrm{Al}_{2} \mathrm{O}_{3}$ with a Si/Al ratio similar to the EZ. Adequate amounts of tetraethyl orthosilicate (SigmaAldrich, $98 \%$ ) and aluminum isopropoxide (Sigma-Aldrich, $\geq 98 \%$ ) to obtain a Si/Al molar ratio equal to 3 were added to $12 \mathrm{~mL}$ of water and $28 \mathrm{~mL}$ of ethanol, and the $\mathrm{pH}$ was raised to 10 by the addition of ammonia (Merck, 28-30\%). The resulting gel was then kept at $25{ }^{\circ} \mathrm{C}$ for $24 \mathrm{~h}$, dried at $100{ }^{\circ} \mathrm{C}$ overnight, and finally calcined at $500{ }^{\circ} \mathrm{C}$ for 6 hours at a heating rate of 2 ${ }^{\circ} \mathrm{C} \cdot \mathrm{min}^{-1}$. Two zeolites were used as reference catalysts: ZSM-5 with $\mathrm{Si} / \mathrm{Al}$ ratio of 40 , provided by Süd-Chemie (ZSM-5(40)), and ZSM-5 with Si/Al ratio of 13 provided by Zeolyst (ZSM$5(13))$.

The hybrid catalysts were prepared according to the following procedure. The CZA and zeolite powder were grinded in an agate mortar at a mass ratio of $5: 3(\mathrm{w} / \mathrm{w})$ to form a homogeneous hybrid catalyst, followed by pressuring the mixture into tablets and crushing them to $90-150$ mesh size particles before the reaction.

\section{Characterization}

The powder X-ray diffraction of the samples was measured employing a PANalytical X'Pert Pro diffractometer with $\mathrm{Cu} \mathrm{K} \alpha$ radiation $(\lambda=1.5418 \AA, 45 \mathrm{kV}, 40 \mathrm{~mA})$. The electron micrographs of the prepared crystals were collected by MIRA-LMH (Tescan) SEM equipped with field emission gun. For TEM analysis, a JEOL-2011F having an acceleration voltage of 200 $\mathrm{kV}$ was used. Prior to TEM characterization, the samples were dispersed in ethanol solution with ultrasonic treatment for $30 \mathrm{~min}$ and then dropped onto a carbon film on a copper grid.

The elemental analysis of the studied ZSM-5 materials was performed by inductively coupled plasma-atomic emission spectrometer (ICPAES) OPTIMA 4300 DV (Perkin-Elmer). 
The chemical composition of the samples was analyzed by inductively coupled plasma-atomic emission spectroscopy (ICP-AES) using an OPTIMA 4300 DV (Perkin-Elmer) instrument.

The porosity of the samples was evaluated by recording the nitrogen adsorption/desorption isotherms using a Micrometrics ASAP 2020 volumetric adsorption analyzer. Samples were degassed at $300{ }^{\circ} \mathrm{C}$ under a vacuum overnight prior to the measurement. The specific surface area, $\mathrm{S}_{\mathrm{BET}}$, was calculated by the Brunauer-Emmett-Teller method, and the total pore volume was taken from the nitrogen adsorbed volume at $\mathrm{p} / \mathrm{p}_{0}=0.99$. The micropore volume was estimated by the t-plot method, while the mesoporous volume is the difference between the total and micropore volumes, $\mathrm{V}_{\text {meso }}=\mathrm{V}_{\text {total }}-\mathrm{V}_{\text {mic }}$.

Solid-state MAS NMR spectra were measured on a Bruker Avance III-HD 500 (11.7 T) spectrometer using $4 \mathrm{~mm}-\mathrm{OD}$ zirconia rotors. Single-pulse excitation ( $30^{\circ}$ flip angle) of $3 \mu \mathrm{s}$ was used for ${ }^{29}$ Si MAS NMR experiment and $30 \mathrm{~s}$ of recycling delay at spinning frequency of $12 \mathrm{kHz}$. ${ }^{27} \mathrm{Al}$ MAS NMR was performed with a 12 pulse (selective pulse) and a spinning speed of 14.5 $\mathrm{kHz}$.

The IR spectra of as-synthesized porous materials were recorded on a Nicolet Impact 410 FTIR spectrometer equipped with a DTGS detector range $400-4000 \mathrm{~cm}^{-1}$. The solid materials were pressed into self-supported thin pellets. Pre-treatment in the IR cell connected to the vacuum line at $120^{\circ} \mathrm{C}\left(0.33{ }^{\circ} \mathrm{C} \mathrm{min}{ }^{-1}\right)$ for $1.5 \mathrm{~h}$ and at $500{ }^{\circ} \mathrm{C}\left(1.27{ }^{\circ} \mathrm{C} \mathrm{min}{ }^{-1}\right)$ for $2 \mathrm{~h}$ under the pressure of $10^{-6}$ torr preceded acquiring the spectra at room temperature. The obtained spectra were normalized to the weight of the self-supported disc. Pyridine adsorption was conducted at $150{ }^{\circ} \mathrm{C}$. After pressure of 1 torr was established at equilibrium, the cell was evacuated at room temperature. The strength of the interactions between the zeolite and the probe molecules, the samples were step-wise heated to $50-400{ }^{\circ} \mathrm{C}$ (step $50{ }^{\circ} \mathrm{C}$ ), and the spectra were taken at each 
temperature. After background subtraction, the amount of Brönsted and Lewis acid sites at each desorption temperature was calculated from the integrated area of the bands of adsorbed pyridine at 1545 and $1455 \mathrm{~cm}^{-1}$ by using the extinction coefficients reported earlier [34].

\section{DFT modeling}

Periodic DFT calculations were performed using the Vienna Ab initio Simulation Package (VASP) [35,36,37]. The Perdew-Burke-Ernzerhof (PBE) exchange-correlation functional in combination with the projector augmented waves (PAW) method was used $[38,39,40]$. The kinetic cutoff energy of the plane-wave basis set was set to $500 \mathrm{eV}$. A Gaussian smearing of 0.05 eV was applied to band occupations around the Fermi level, and the total energies were extrapolated to $\sigma \rightarrow 0$. Brillouin zone sampling was restricted to the $\Gamma$ point [41]. Van der Waals interactions were described by the dispersion-corrected DFT-D3 method with Becke-Johnson (BJ) damping [42]. Convergence was assumed with the force on each atom below $0.05 \mathrm{eV} \AA^{-1}$.

The ZSM-5 zeolite was simulated by an orthogonal MFI unit cell $\left(\mathrm{Si}_{96} \mathrm{O}_{192}\right)$ [43]. The Brönsted acid sites (BASs) were introduced as charge-compensating cations by the isomorphous substitution of Al for lattice Si atoms. Two MFI models with varying Si/Al ratios of 47 and 3.8 (Figure S1, MFI-47 and MFI-3.8) were considered to model the crystalline zeolites. The lattice parameters were optimized for these defect-free zeolite models (MFI-47, $a=20.02 \AA, b=19.90$ $\AA, c=13.38 \AA, \alpha=\beta=\gamma=90^{\circ}$; MFI-3.8, $a=20.21 \AA, b=19.81 \AA, c=13.34 \AA, \alpha=\beta=\gamma=$ $90^{\circ}$ ). To simulate the embryonic MFI zeolite, a $1 \times 2 \times 2$ supercell was first constructed from the MFI-47 model. Then a part of zeolite framework atoms was removed to build the defect model (Figure S1, MFI-defect), in which the BASs (sites 1 and 2) are surrounded by a different portion of the framework atoms as present in the crystalline MFI. The dangling bonds at the edges were 
saturated by hydrogen atoms. Fully relaxed optimizations were performed with fixed lattice parameters. The BASs at the intersection of MFI channel were considered for the evaluation of acid strength, which was determined by the pyridine adsorption energy ( $\left.\Delta E_{\text {ads }}\right)$ computed as

$$
\Delta E_{\mathrm{ads}}=E_{\mathrm{model}-\mathrm{py}}-E_{\mathrm{model}}-E_{\mathrm{py}},
$$

where $E_{\mathrm{model}-\mathrm{py}}, E_{\mathrm{model}}$, and $E_{\mathrm{py}}$ are the electronic energies of pyridine adsorption complex, freestate pyridine, and bare zeolite model, respectively.

\section{Catalysis}

The DME synthesis reaction was carried out in a fixed-bed stainless-steel tubular reactor (d=8 mm) operating at 20 bar. The catalyst loading was typically $0.5 \mathrm{~g}$. Before reaction, the samples were reduced in hydrogen flow with a flow rate of $30 \mathrm{~cm}^{3} / \mathrm{min}$. During the reduction, the temperature was increased to $290{ }^{\circ} \mathrm{C}$ with a ramping rate of $2{ }^{\circ} \mathrm{C} / \mathrm{min}$ and then kept at this temperature for $7 \mathrm{~h}$. After reduction, the hydrogen flow was switched to a syn-gas mixture with $\mathrm{H}_{2} / \mathrm{CO}$ molar ratio of 2 . The reaction was carried out at $260{ }^{\circ} \mathrm{C}$ under a pressure of 20 bar maintained using a back pressure regulator, and the space velocity of $3600 \mathrm{~cm}^{3}$ gas $/ \mathrm{gcat}^{-1}$ $\left(\mathrm{WHSV}=1.7 \mathrm{~h}^{-1}\right)$. Carbon monoxide contained 5\% nitrogen, which was used as an internal standard for conversion and selectivity calculations. The products were sampled from the highpressure side and analyzed using an online gas chromatograph with a TCD $\left(\mathrm{N}_{2}, \mathrm{CO}, \mathrm{CO}_{2}\right.$, and $\left.\mathrm{CH}_{4}\right)$ and a FID (MeOH, DME, and hydrocarbons) detectors. The $\mathrm{CO}$ conversion (X) was calculated based on the molar flow rate of $\mathrm{CO}$ in the feed $\left(\mathrm{F}_{\mathrm{CO} \text { in }}\right)$ and in the outlet streams $\left(\mathrm{F}_{\mathrm{COout}}\right): \mathrm{X}_{\mathrm{CO}}(\%)=\left(1-\left(\mathrm{F}_{\mathrm{COout}} / \mathrm{F}_{\mathrm{CO} \text { in }}\right)\right) \times 100$. 
The selectivity to the product $p$ with flow rate $n_{p}$ containing $C_{p}$ carbon atoms was determined on a carbon basis and expressed in mol \% of carbon converted to a specific reaction product:

$\mathrm{S}$ to the product $\mathrm{p}(\%)=\mathrm{n}_{\mathrm{p}} \times \mathrm{C}_{\mathrm{p}} /\left(\mathrm{F}_{\text {COin }}-\mathrm{F}_{\text {COout }}\right) \times 100$.

\section{Results and discussion}

\section{Preparation of embryonic zeolite}

In the scope of this study was prepared embryonic zeolite material using TPAOH, a structure-directing agent typical for the synthesis of MFI-type zeolite material. In contrast to previous studies $\left[{ }^{12-14}\right]$, where EZs with relatively high $\mathrm{Si} / \mathrm{Al}(>50)$ ratio were prepared, the $\mathrm{Si} / \mathrm{Al}$ ratio was kept low and a particular source where the bond $\mathrm{Si}-\mathrm{O}-\mathrm{Al}$ already exists, di-secbutoxyaluminoxytriethoxysilane (DSBATES), was employed. An additional Si source, tetraethylorthosilicate (TEOS), enabled achieving Si/Al ratio of 5 in the initial synthesis mixture was also employed. Thus, the initial mixture contained a higher Al amount than TPA-templated ZSM-5 can integrate into the zeolite framework. Consequently, aluminum species of different coordination and acid strength can be expected. The solid recovered after 10 days of hydrothermal treatment was further treated with $\mathrm{NH}_{4} \mathrm{Cl}$ solution prior to calcination to remove the soluble aluminosilicates deposited on the zeolite precursor.

Scanning electron microscopy (SEM) has been used to investigate zeolite morphology. Representative SEM micrographs of zeolite samples are displayed in Figure 1. The commercial zeolite ZSM-5(40) (Figure 1A) contains rather small aggregates with a size of about $0.5 \mu \mathrm{m}$. These aggregates are built of smaller zeolite nanoparticles (20-50 nm).ZSM-5(13) (Figure 1B) is 
composed of several micron large aggregates built of well-shaped 100-500 nm zeolite crystals with sharper edges. The TEM inspection of the EMB sample showed ultra-small (ca.5 nm) particles, which are loosely agglomerated (Figure 1C and 1D). They do not exhibit specific morphological features and, at a closer look, seem to be built up of even smaller entities Figure $1 D$.

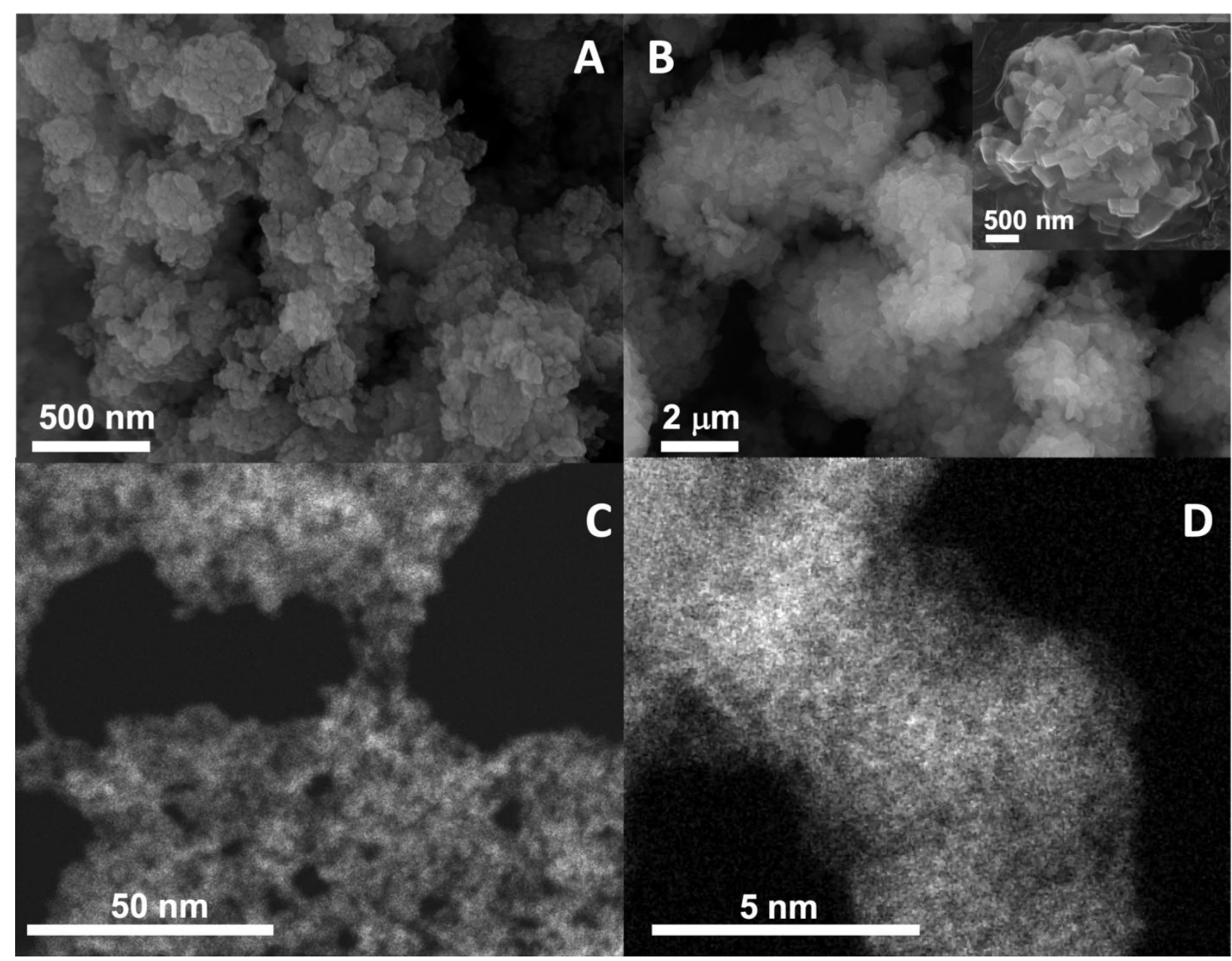

Figure 1. SEM images of ZSM-5(40) (A) and ZSM-5(13) (B) zeolites and TEM images of embryonic zeolite $(E M B)$ particles at low $(C)$ and high $(D)$ magnification. 
The physicochemical characteristics of the EMB and conventional zeolite are summarized in Table 1. The EMB material with a bulk Si/Al ratio of 4.83 is X-ray amorphous compared to a completely crystalline reference ZSM-5 samples (Figure 2A). The two ZSM-5 materails exhibit the typical of zeolite-type microporous materials type I adsorption isotherm with a steep uptake at low relative pressure. Besides, a second uptake at high relative pressure originating from the textural mesopores generated by the zeolite nanocrystals can be observed for ZSM-5(40) material. EMB material presents type $\mathrm{Ib} \mathrm{N}_{2}$ adsorption isotherm (Figure 2B), which ensues from extra-large micropores $\left[{ }^{44}\right]$. The isotherm does not exhibit additional features revealing the high uniformity of the material. Further, it presents micropore volume of $0.11 \mathrm{~cm}^{3} \mathrm{~g}^{-1}$ and $\mathrm{S}_{\mathrm{BET}}$ of 363 $\mathrm{m}^{2} \mathrm{~g}^{-1}$, which are lower than for the crystalline materials (Table 1), indicating a somewhat less open microporous structure of the embryonic material.

Table 1. Framework composition, porosity, and concentration of Brønsted $(B)$ and Lewis $(L)$ acid sites determined by IR analysis of adsorbed pyridine (Py) of the studied samples.

\begin{tabular}{|c|c|c|c|c|c|c|c|c|}
\hline \multirow{3}{*}{ Zeolite } & \multirow{3}{*}{$\mathrm{Si} / \mathrm{Al}^{\mathrm{ICP}}$} & \multicolumn{4}{|c|}{$\mathrm{N}_{2}$ adsorption } & \multirow{2}{*}{\multicolumn{3}{|c|}{$\begin{array}{r}\text { Py adsorption } \\
250^{\circ} \mathrm{C} \\
\end{array}$}} \\
\hline & & \multirow[b]{2}{*}{$\begin{array}{l}S_{\mathrm{BET}} / \\
\mathrm{m}^{2} \mathrm{~g}^{-1}\end{array}$} & \multirow[b]{2}{*}{$\begin{array}{l}V_{\text {mic }} / \\
\mathrm{cm}^{3} \mathrm{~g}^{-1}\end{array}$} & \multirow[b]{2}{*}{$\begin{array}{l}V_{\text {meso }} / \\
\mathrm{cm}^{3} \mathrm{~g}^{-1}\end{array}$} & $150^{\circ} \mathrm{C}$ & & & \\
\hline & & & & & $\begin{array}{c}n(\mathrm{~B}) / \\
\mu \mathrm{mol} \mathrm{g}\end{array}$ & $\begin{array}{c}n(\mathrm{~L}) / \\
\mu \mathrm{mol} \mathrm{g}\end{array}$ & $\begin{array}{c}n(\mathrm{~B}) / \\
\mu \mathrm{mol} \mathrm{g}\end{array}$ & $\begin{array}{c}n(\mathrm{~L}) / \\
\mu \mathrm{mol} \mathrm{g}\end{array}$ \\
\hline EMB & 4.83 & 363 & 0.11 & 0.069 & 46 & 355 & 23 & 266 \\
\hline ZSM-5(40) & 40 & 398 & 0.17 & 0.426 & 144 & 72 & 85 & 42 \\
\hline ZSM-5(13) & 13 & 393 & 0.16 & 0.06 & 376 & 366 & 295 & 241 \\
\hline
\end{tabular}

The ${ }^{27} \mathrm{Al}$ MAS NMR analysis found a range of $\mathrm{Al}$ species in the studied embryonic zeolite, whereas the crystalline ZSM-5 samples exhibit only a resonance at 54 ppm corresponding to tetrahedral framework Al (Figure 2C). Further, the IR spectrum of the EMB material displays exclusively isolated silanols $\left(3720-3750 \mathrm{~cm}^{-1}\right)$ that were observed in the ZSM-5(40) and ZSM5(13) as well, yet their different distribution in these two samples brings about different band 
profiles (Figure 2). Moreover, the crystalline MFI-type material possesses Brönsted acid sites, as evidenced by a well-expressed $3612 \mathrm{~cm}^{-1}$ band. The IR data on the ZSM-5(40) and the ZSM5(13) samples reveal the presence of highly distorted tetrahedral Al species partially detached from the zeolite framework $\left(3666 \mathrm{~cm}^{-1}\right)$ and octahedral extra-framework $\mathrm{Al}\left(3880 \mathrm{~cm}^{-1}\right)$ [45]. Indeed, there are structural defects in the reference samples, yet ${ }^{27} \mathrm{Al}$ NMR was not able to detect them, which can be explained by their low fraction combined with the "invisible aluminum" effect.
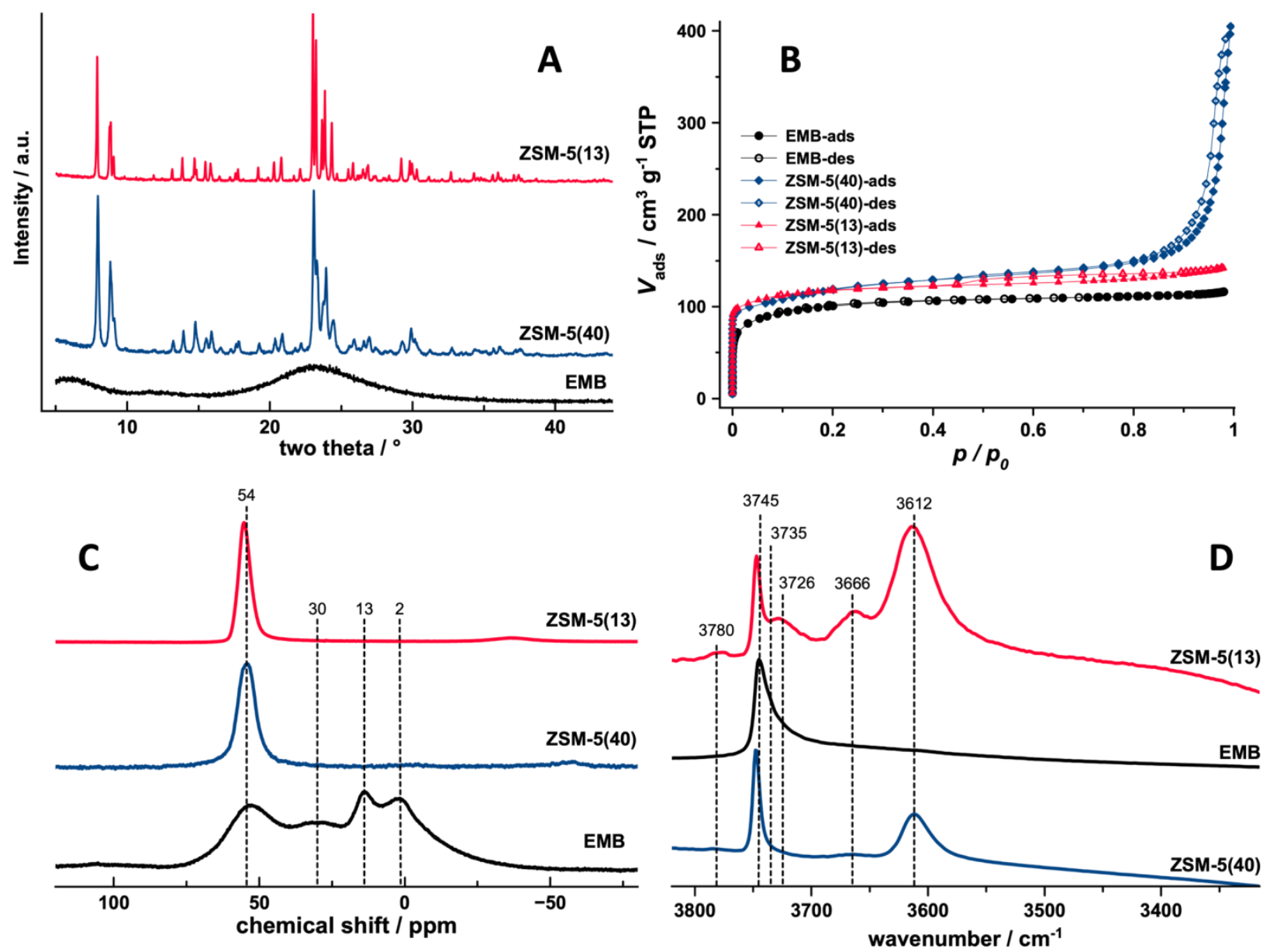

Figure 2. Comparison of calcined ZSM-5(40) and ZSM-5(25) samples with the EMB zeolite:

A) XRD patterns, B) $N_{2}$ adsorption/desorption isotherms, C) ${ }^{27}$ Al MAS NMR spectra, D) FTIR spectra in the $\mathrm{OH}$ groups region. 
To evaluate the acid site density, the pyridine probe molecule was adsorbed on the samples, and the IR measured data are listed in Table 1. The embryonic and crystalline materials possess Brønsted and Lewis acid sites. Chemically adsorbed pyridine exhibits a set of bands: two bands at 1545 and $1620 \mathrm{~cm}^{-1}$ assigned to pyridinium ion $\left(\mathrm{PyH}^{+}\right)$, two bands at 1455 , and $1620 \mathrm{~cm}^{-1}$ related to coordinatively adsorbed pyridine on Lewis sites [46] (Figure 3). The band at 1490 $\mathrm{cm}^{-1}$ was attributed to Py species adsorbed on Lewis and Brönsted sites.

In agreement with the IR spectra of the OH groups, ZSM-5(40) has a moderate number of Brönsted sites and twice lower quantity of Lewis acid sites, while the ZSM-5(13) presents a rather high amount of both Brönsted and Lewis acid sites. The number of Brönsted sites in the EMB sample is lower than in the reference materials and comparable with the previously reported embryonic zeolites [14]. Further, the embryonic zeolite possesses a substantial amount of Lewis sites, which are associated with the extra-framework Al detected by NMR. The strength of the acid sites has been compared by analysis of the desorption of Py with an increase of the temperature in the infrared cell (Figure 3). Conventional ZSM-5(13) demonstrates a gradual decrease in the concentration of adsorbed Py with the increase of the temperature. Zeolite ZSM5(40) presents a higher desorption rate with the increase of the temperature. At the same time, in the embryonic zeolite, almost full desorption of Py is achieved already at $300{ }^{\circ} \mathrm{C}$. These results indicate significantly lower strength of the acid sites in the embryonic zeolite in comparison with commercial ZSM-5 reference materials. Thus, in order to understand the acidity difference between the crystalline and embryonic MFI zeolites we performed DFT calculations. 

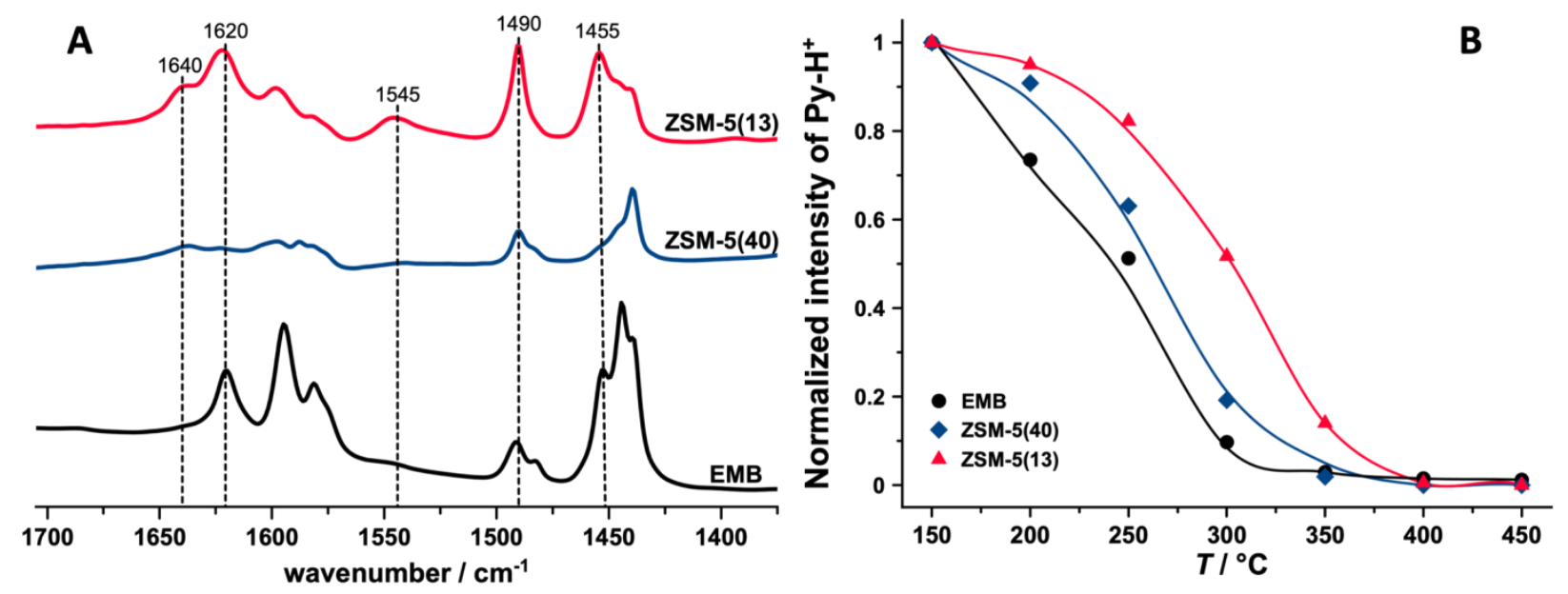

Figure 3. Py adsorption over zeolites at $150^{\circ} \mathrm{C}(\mathrm{A})$ and normalized amount of Py adsorbed over Brønsted acid sites versus temperature of Py desorption for ZSM-5 and EMB (B).

\section{DFT modeling}

The crystalline MFI zeolites were simulated with two different Si/Al ratios of 47 and 3.8 (Figure S1, SI MFI-47 and MFI-3.8), for which the acid strength was investigated by determining the pyridine adsorption energy $\left(\Delta E_{\mathrm{ads}}\right)$. The Brönsted acid sites (BASs) located at the channel intersection were considered, and the adsorption of pyridine leads to the proton transfer, which forms the protonated pyridine and the anionic zeolite framework (Figure 4, MFI47-py and MFI-3.8-py). The computed $\Delta E_{\text {ads }}$ are -219 and $-201 \mathrm{~kJ} / \mathrm{mol}$ for the MFI-47 and MFI3.8 zeolites, respectively, suggesting a stronger acid strength of BAS in MFI-47 than in MFI-3.8. This trend indicates the acid strength increases with increasing $\mathrm{Si} / \mathrm{Al}$ ratio, which is a widely reported phenomenon in zeolite chemistry $[47,48,49]$. The embryonic MFI was modeled by a defect model, which contains two BASs with partially eliminated surrounding framework atoms (Figure S1, MFI-defect). The adsorption of pyridine on the two BASs in the MFI-defect model affords the $\Delta E_{\text {ads }}$ of -182 and $-139 \mathrm{~kJ} / \mathrm{mol}$, respectively (Figure 4, MFI-defect-sitel-py and MFI-defect-site2-py), which signifies the weaker acid strength of these sites in comparison with 
the BASs in the crystalline MFI zeolites. In addition, the decrease in the acid strength is more significant when a larger portion of the framework atoms around the BASs were removed $(-182$ vs. $-139 \mathrm{~kJ} / \mathrm{mol}$ for MFI-defect-site1-py and MFI-defect-site2-py). This model matches well with the structure of EMB, where a substantial part of the unit cell is missing. The acidity trend for the crystalline and embryonic MFI suggests the gradual formation of defect-free framework structures promotes a higher acid strength of the BASs in zeolites. The presented DFT results coincide with the experimental observation, which suggests the acid strength of the BASs is weaker in the embryonic MFI than in the crystalline ones.
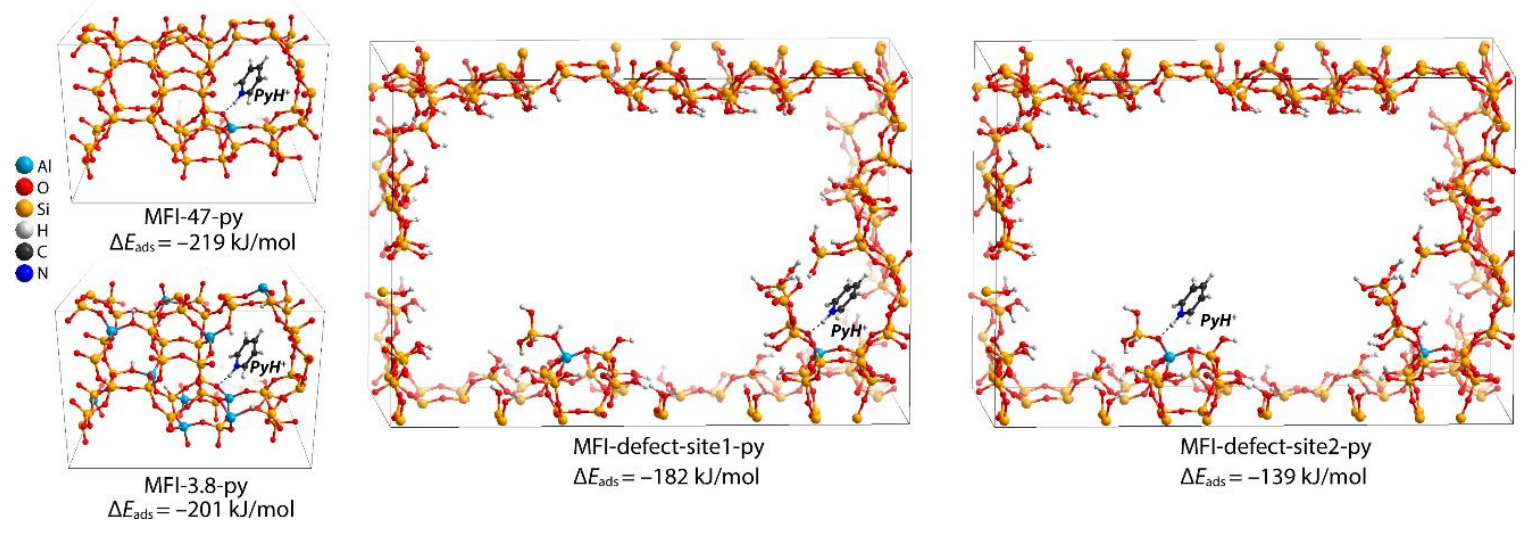

Figure 4. Optimized structures of pyridine adsorption in the crystalline MFI zeolites with different $\mathrm{Si} / \mathrm{Al}$ ratios [MFi-47-py $(\mathrm{Si} / \mathrm{Al}=47)$ and $\mathrm{MFI-3.8-py}(\mathrm{Si} / \mathrm{Al}=3.8)]$ and the embryonic MFI zeolite represented by a defect model (Si/Al = 71) containing two BASs (MFI-defect-sitelpy and defect-site2-py). The adsorption of pyridine on the BASs leads to the formation of protonated pyridine $\left(\mathrm{pyH}^{+}\right)$confined in zeolites. The acidity strength of the BASs was determined by the pyridine adsorption energy $\left(\Delta E_{a d s}\right)$.

\section{DME synthesis}

The catalytic test of DME synthesis from syngas has been conducted over a mechanical mixture of CZA with embryonic zeolite in comparison with industrial zeolite and amorphous aluminosilicate. The catalytic tests were performed at $260{ }^{\circ} \mathrm{C}$ and 20 bar at $\mathrm{H}_{2} / \mathrm{CO}$ ratio 2 . 
Dimethyl ether, methanol, carbon dioxide, hydrocarbons, and water were the major products of the reaction. We have conducted hydrogenation of CO over CZA catalyst at GHSV 3.6 L/g h (Figure 5). The CZA catalyst has demonstrated conversion of CO $17.8 \%$, which is close to thermodynamic equilibrium for hydrogenation of $\mathrm{CO}$ to methanol [50]. The main product of the reaction, in this case, is methanol $(88.7 \%)$ with a small contribution of $\mathrm{CO}_{2}$ and DME due to the weak acidity of the catalyst.

An addition of methanol dehydration function to the methanol synthesis catalysts should shift the thermodynamic equilibrium and favors DME formation by methanol dehydration over acid sites. It is interesting to note that the mechanical mixture of CZA with amorphous aluminosilicate does not change activity with CO conversion close to $22 \%$. However, weak acidity of aluminosilicate induces an increase of the selectivity to DME to $65 \%$ at $33 \%$ of selectivity to methanol. Figure 5 displays CO conversion for the mechanical mixture of CZA with embryonic zeolite and commercial ZSM-5 zeolites. The conversion of CO in the presence of zeolites increases to $65-70 \%$, indicating a significant shift of the equilibrium of the reaction by methanol dehydration to DME. The activity increases in the row: ZSM-5(13) $<$ ZSM-5(40) $<$ EMB from 65 to $73.5 \%$.

Methanol synthesis over the copper catalysts is a reversible reaction. At the reaction temperatures used in this work, the yield of methanol from $\mathrm{H}_{2} / \mathrm{CO}$ over a methanol synthesis catalyst depends on the thermodynamic equilibrium rather than on the reaction kinetics. The addition of methanol dehydration function in the form of zeolite to the methanol synthesis catalyst shifts the thermodynamic equilibrium and favors DME formation. Thus, in bifunctional copper zeolite catalyst the rate of the reaction will depend both on the rates of methanol synthesis and dehydration reactions. The most important in this case should be the transport rate of 
methanol as intermediate from $\mathrm{Cu}$ catalyst to zeolite. It explains why the ultra-small embryonic zeolite with relatively weak acidity provides significantly higher activity for DME synthesis in comparison with large crystal ZSM-5 catalysts possessing strong acidity. Indeed, the amount of acid sites decreases in the direction reverse to activity ZSM-5(13)>ZSM-5(40)>EMB, and the highest content of acid sites in ZSM-5(13) cannot compensate large size of zeolite crystals and diffusion limitations related to transfer of methanol from CZA to zeolite. The same effect has been observed earlier using different size nanocrystals of ZSM-5 [30].

The high efficiency of embryonic zeolite in the catalytic performance of DME synthesis can be assigned to the enhanced transport of methanol produced on the CZA catalyst to the intimately mixed ultra-small embryonic zeolites. In this case, smaller, highly open zeolitic particles reduce methanol transport limitations and diffusion paths inside the pores. The dehydration, in this case, occurs both inside the zeolite pores and on the external surface.
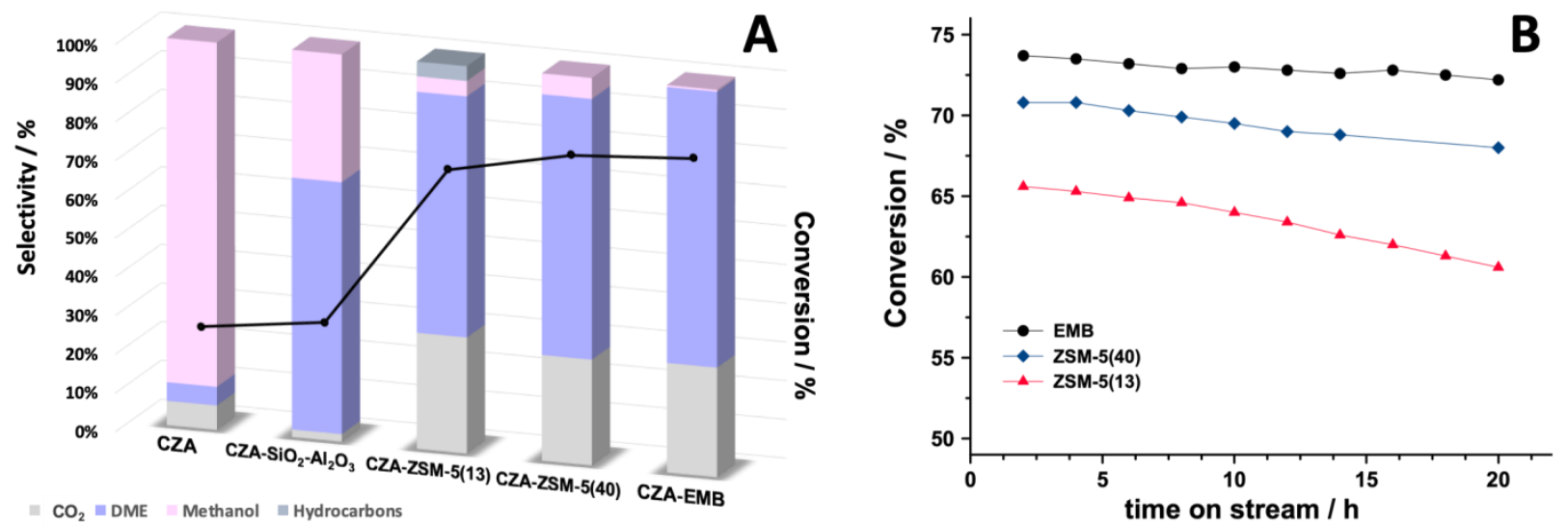

Figure 5. Comparison of a mechanical mixture of ZSM-5, EMB, and aluminosilicate (SiO ${ }_{2}$ $\left.\mathrm{Al}_{2} \mathrm{O}_{3}\right)$ with $\mathrm{CZA}$, and pure CZA: A) Carbon monoxide conversion as a function of GHSV $\left.\left(\mathrm{T}=260^{\circ} \mathrm{C}, \mathrm{P}=2 \mathrm{O} \mathrm{bar}, \mathrm{H}_{2} / \mathrm{CO}=2\right), \mathrm{B}\right)$ selectivity to the products $\left(\mathrm{T}=260^{\circ} \mathrm{C}, \mathrm{P}=2 \mathrm{O} \mathrm{bar}, \mathrm{H}_{2} / \mathrm{CO}=2\right.$, 
GHSV=3.6 L/gh), and C) comparison of deactivation during DME synthesis from syngas over CZA/ZSM-5 and CZA/EMB $\left(T=260^{\circ} \mathrm{C}, \mathrm{P}=20 \mathrm{bar}, \mathrm{H}_{2} / \mathrm{CO}=2, \mathrm{GHSV}=3.6 \mathrm{~L} / \mathrm{gh}\right)$.

The selectivities for zeolite catalysts have been compared at the conversion close to $70 \%$ in Figure 5. The selectivity to carbon dioxide is about $30 \%$ for the catalysts, which is close to the stoichiometric transformation of formed water during WGS from $\mathrm{CO}$ to $\mathrm{CO}_{2}$. Another product of syngas transformation over embryonic zeolite is DME, with selectivity close to $71 \%$ with only traces of other products. The selectivity to DME decreases in the row EMB > ZSM-5(40) > ZSM-5(13) with selectivity $64.6 \%$ for ZSM-5(13). The reaction of syngas transformation over ZSM-5(40) provides additionally to DME a significant amount of methanol (5.4\%), which is the result of not full methanol dehydration to DME. Additionally to the methanol, CZA-ZSM-5(13) provides the formation of light hydrocarbons (ethylene, propylene...) with selectivity $3.8 \%$. The presence of hydrocarbons indicates a deeper dehydration of methanol over strong acid similar to MTO process [45]. This could be explained by the highest acidity of ZSM-5(13) zeolite in comparison with ZSM-5(40) and EMB. Consequently, the highest selectivity to DME over embryonic zeolite can be assigned to its mild acidity, besides the enhanced transport properties. According to pyridine adsorption and DFT modeling embryonic zeolite possesses mild acidity induced by a defected structure, which provides efficient dehydration of methanol to DME without a deeper transformation toward hydrocarbons.

Figure 5 displays $\mathrm{CO}$ conversion measured on the catalysts as a function of reaction time. Carbon monoxide conversion decreases over ZSM-5(13) from 65.6 to $60.6 \%$ for $20 \mathrm{~h}$ with time on stream, which can be attributed to the catalyst deactivation. ZSM-5(40) provides higher stability during DME synthesis with a decrease of the CO conversion from 70.8 to $68 \%$. It is worthy to note that the embryonic zeolite provides much higher stability, with only a slight 
catalyst deactivation in time. Previous reports suggest that the deactivation of CZA@ZSM-5 catalysts can be due to several phenomena: copper sintering, copper oxidation, and migration to the cationic positions of zeolite, coke deposition [31,51,32,52]. All these effects are induced by the strong acid sites interacting with copper or generating coke species. Earlier, we have identified that external acidity is a particularly important factor in catalyst deactivation due to close contact with the CZA catalyst [32]. The fast deactivation rate of the catalyst based on ZSM-5(13) can be explained by the strong acidity of zeolite, leading to interaction and oxidation of $\mathrm{Cu}$. Moderate acidity of embryonic zeolites attenuates the negative effects related to copper migration and coke formation. Moreover, the embryonic zeolites with their cage-like structure of a few nano-meter sizes do not exhibit strong external acidity in term of a crystalline zeolite-type material. Thus, these materials are particularly appropriate for preparing a hybrid catalyst for DME synthesis from syngas.

To conclude, our results show significantly higher activity, selectivity, and stability toward DME synthesis using embryonic zeolite in comparison with crystalline ZSM-5. The mild acidity and small size of embryonic zeolite nanoparticles mixed with $\mathrm{Cu}$ catalyst provide efficient and stable dehydration of intermediate methanol to DME without the formation of side hydrocarbons.

\section{Conclusion}

The obtained results show an excellent catalytic performance of embryonic zeolite mixed with $\mathrm{CuO}-\mathrm{ZnO}-\mathrm{Al}_{2} \mathrm{O}_{3}$ catalyst for direct DME synthesis. The catalyst demonstrates high activity, selectivity, and stability in comparison with conventional ZSM-5 catalyst. The set of experimental data revealed that the superior catalytic performance is an interplay between several phenomena: 
$\checkmark$ Embryonic zeolite contains ultra-small nanoparticles $(<5 \mathrm{~nm})$ in agglomerates;

$\checkmark$ The embryonic zeolite has different types of Al sites in the structure with a lower strength of the acid sites than conventional zeolites. The DFT modeling supports the experimental data and confirms the decrease of acid strength with the lost of structure ordering, which is the case of embryonic zeolite.

Ultra-small nanoparticles $(5 \mathrm{~nm})$ in agglomerates of embryonic zeolite provide enhanced methanol transport phenomena in bifunctional hybrid catalysts from the copper catalyst to the acid sites, which results in the high activity of the catalyst at low content of the acid sites. The low strength of the acid sites also contributes to the significantly higher selectivity to DME and high stability of the catalyst. The results obtained in this manuscript indicate a new methodology for catalyst design for direct DME synthesis from syngas.

Acknowledgments

Vitaly ???????????????????, V.V. acknowledges the support from the Industrial Chair ANRTOTAL "Nanoclean Energy”(ANR-??-000).

ASSOCIATED CONTENT

Supporting Information. Computational Modelling; Py desorption.

\section{AUTHOR INFORMATION}

\section{Corresponding Author}

Vitaly Ordomsky: vitaly.ordomsky@univ-lille.fr;

Unité de Catalyse et de Chimie du Solide

UMR 8181 CNRS, Ecole Centrale de Lille, Université de Lille

Bât. C3, 59655 Villeneuve d'Ascq, France 
Valentin Valtchev: valentin.valtchev@ensicaen.fr

Normandie Univ, ENSICAEN, UNICAEN, CNRS, Laboratoire Catalyse et Spectrochimie, 6

Boulevard Maréchal Juin, Caen, France

\section{Author Contributions}

The manuscript was written through the contributions of all authors. All authors have given approval to the final version of the manuscript.

\section{REFERENCES}

1. R. Millini, G. B., Zeolites in Catalysis: Properties and Applications. J. Čejka, R. E. M., P. Nachtigall, Ed. The Royal Society of Chemistry: 2017; pp 1-36.

2. J.B. Nagy, P. B., I. Hannus, I. Kiricsi, Synthesis and Use of Zeolitic Microporous Materials. DecaGen, Szeged-Szõreg: 1998.

3. $\quad$ Pérez-Ramírez, J.; Christensen, C. H.; Egeblad, K.; Christensen, C. H.; Groen, J. C., Hierarchical zeolites: enhanced utilisation of microporous crystals in catalysis by advances in materials design. Chemical Society Reviews 2008, 37 (11), 2530-2542.

4. Gallego, E. M.; Li, C.; Paris, C.; Martín, N.; Martínez-Triguero, J.; Boronat, M.; Moliner, M.; Corma, A., Making Nanosized CHA Zeolites with Controlled Al Distribution for Optimizing Methanol-to-Olefin Performance. 2018, 24 (55), 14631-14635.

5. $\quad$ Zhang, Q.; Xiang, S.; Zhang, Q.; Wang, B.; Mayoral, A.; Liu, W.; Wang, Y.; Liu, Y.; Shi, J.; Yang, G.; Luo, J.; Chen, X.; Terasaki, O.; Gilson, J.-P.; Yu, J., Breaking the Si/Al Limit of Nanosized $\beta$ Zeolites: Promoting Catalytic Production of Lactide. Chemistry of Materials 2020, 32 (2), 751-758.

6. Awala, H.; Gilson, J. P.; Retoux, R.; Boullay, P.; Goupil, J. M.; Valtchev, V.; Mintova, S., Template-free nanosized faujasite-type zeolites. Nature materials 2015, 14 (4), 44751 .

7. Peng, C.; Liu, Z.; Yonezawa, Y.; Linares, N.; Yanaba, Y.; Trujillo, C. A.; Okubo, T.; Matsumoto, T.; García-Martínez, J.; Wakihara, T., Testing the limits of zeolite structural flexibility: ultrafast introduction of mesoporosity in zeolites. Journal of Materials Chemistry A 2020, 8 (2), 735-742.

8. Valtchev, V.; Balanzat, E.; Mavrodinova, V.; Diaz, I.; El Fallah, J.; Goupil, J.-M., High Energy Ion Irradiation-Induced Ordered Macropores in Zeolite Crystals. Journal of the American Chemical Society 2011, 133 (46), 18950-18956.

9. Hernando, H.; Hernández-Giménez, A. M.; Ochoa-Hernández, C.; Bruijnincx, P. C. A.; Houben, K.; Baldus, M.; Pizarro, P.; Coronado, J. M.; Fermoso, J.; Čejka, J.; Weckhuysen, B. M.; Serrano, D. P., Engineering the acidity and accessibility of the zeolite ZSM-5 for efficient bio-oil upgrading in catalytic pyrolysis of lignocellulose. Green Chemistry 2018, 20 (15), 34993511 . 
10. Lobo, R. F.; Tsapatsis, M.; Freyhardt, C. C.; Khodabandeh, S.; Wagner, P.; Chen, C.Y.; Balkus, K. J.; Zones, S. I.; Davis, M. E., Characterization of the Extra-Large-Pore Zeolite UTD-1. Journal of the American Chemical Society 1997, 119 (36), 8474-8484.

11. K.-G. Haw, J.-M. G., J.-P. Gilson, V. Valtchev, N. Nesterenko, D. Minoux, J.-P. Dath Catalyst compositions comprising ultra-small size molecular sieves crystals deposited on a porous material. WO2015001004, 2015.

12. Haw, K.-G.; Goupil, J.-M.; Gilson, J.-P.; Nesterenko, N.; Minoux, D.; Dath, J.-P.; Valtchev, V., Embryonic ZSM-5 zeolites: zeolitic materials with superior catalytic activity in 1,3,5-triisopropylbenzene dealkylation. New Journal of Chemistry 2016, 40 (5), 4307-4313.

13. Haw, K.-G.; Gilson, J.-P.; Nesterenko, N.; Akouche, M.; El Siblani, H.; Goupil, J.-M.; Rigaud, B.; Minoux, D.; Dath, J.-P.; Valtchev, V., Supported Embryonic Zeolites and their Use to Process Bulky Molecules. ACS Catalysis 2018, 8 (9), 8199-8212.

14. Akouche, M.; Gilson, J.-P.; Nesterenko, N.; Moldovan, S.; Chateigner, D.; Siblani, H. E.; Minoux, D.; Dath, J.-P.; Valtchev, V., Synthesis of Embryonic Zeolites with Controlled Physicochemical Properties. Chemistry of Materials 2020, 32 (5), 2123-2132.

15. Semelsberger, T. A.; Borup, R. L.; Greene, H. L., Dimethyl ether (DME) as an alternative fuel. Journal of Power Sources 2006, 156 (2), 497-511.

16. Azizi, Z.; Rezaeimanesh, M.; Tohidian, T.; Rahimpour, M. R., Dimethyl ether: A review of technologies and production challenges. Chemical Engineering and Processing: Process Intensification 2014, 82, 150-172.

17. Chen, H.-J.; Fan, C.-W.; Yu, C.-S., Analysis, synthesis, and design of a one-step dimethyl ether production via a thermodynamic approach. Applied Energy 2013, 101, 449-456.

18. Wang, Y.; Chen, Y.; Yu, F.; Pan, D.; Fan, B.; Ma, J.; Li, R., One-step synthesis of dimethyl ether from syngas on ordered mesoporous copper incorporated alumina. Journal of Energy Chemistry 2016, 25 (5), 775-781.

19. Jung, J. W.; Lee, Y. J.; Um, S. H.; Yoo, P. J.; Lee, D. H.; Jun, K.-W.; Bae, J. W., Effect of copper surface area and acidic sites to intrinsic catalytic activity for dimethyl ether synthesis from biomass-derived syngas. Applied Catalysis B: Environmental 2012, 126, 1-8.

20. Yang, G.; Tsubaki, N.; Shamoto, J.; Yoneyama, Y.; Zhang, Y., Confinement Effect and Synergistic Function of H-ZSM-5/Cu-ZnO-A12O3 Capsule Catalyst for One-Step Controlled Synthesis. Journal of the American Chemical Society 2010, 132 (23), 8129-8136.

21. Chinchen, G. C.; Waugh, K. C.; Whan, D. A., The activity and state of the copper surface in methanol synthesis catalysts. Applied Catalysis 1986, 25 (1), 101-107.

22. Hansen, P. L.; Wagner, J. B.; Helveg, S.; Rostrup-Nielsen, J. R.; Clausen, B. S.; Topsøe, H., Atom-Resolved Imaging of Dynamic Shape Changes in Supported Copper Nanocrystals. 2002, 295 (5562), 2053-2055.

23. Wagner, J. B.; Hansen, P. L.; Molenbroek, A. M.; Topsøe, H.; Clausen, B. S.; Helveg, S., In Situ Electron Energy Loss Spectroscopy Studies of Gas-Dependent Metal-Support Interactions in $\mathrm{Cu} / \mathrm{ZnO}$ Catalysts. The Journal of Physical Chemistry B 2003, 107 (31), 77537758.

24. Okamoto, Y.; Fukino, K.; Imanaka, T.; Teranishi, S., Surface characterization of copper(II) oxide-zinc oxide methanol-synthesis catalysts by x-ray photoelectron spectroscopy. 2 . Reduced catalysts. The Journal of Physical Chemistry 1983, 87 (19), 3747-3754.

25. Vishwanathan, V.; Jun, K.-W.; Kim, J.-W.; Roh, H.-S., Vapour phase dehydration of crude methanol to dimethyl ether over Na-modified H-ZSM-5 catalysts. Applied Catalysis A:

General 2004, 276 (1), 251-255. 
26. Fei, J.; Hou, Z.; Zhu, B.; Lou, H.; Zheng, X., Synthesis of dimethyl ether (DME) on modified HY zeolite and modified $\mathrm{HY}$ zeolite-supported $\mathrm{Cu}-\mathrm{Mn}-\mathrm{Zn}$ catalysts. Applied Catalysis A: General 2006, 304, 49-54.

27. Kim, J.-H.; Park, M. J.; Kim, S. J.; Joo, O.-S.; Jung, K.-D., DME synthesis from synthesis gas on the admixed catalysts of $\mathrm{Cu} / \mathrm{ZnO} / \mathrm{Al} 2 \mathrm{O} 3$ and ZSM-5. Applied Catalysis A: General 2004, 264 (1), 37-41.

28. Bae, J. W.; Kang, S.-H.; Lee, Y.-J.; Jun, K.-W., Synthesis of DME from syngas on the bifunctional $\mathrm{Cu}-\mathrm{ZnO}-\mathrm{Al} 2 \mathrm{O} 3 / \mathrm{Zr}$-modified ferrierite: Effect of $\mathrm{Zr}$ content. Applied Catalysis B: Environmental 2009, 90 (3), 426-435.

29. García-Trenco, A.; Valencia, S.; Martínez, A., The impact of zeolite pore structure on the catalytic behavior of $\mathrm{CuZnAl} /$ zeolite hybrid catalysts for the direct DME synthesis. Applied Catalysis A: General 2013, 468, 102-111.

30. Cai, M.; Palčić, A.; Subramanian, V.; Moldovan, S.; Ersen, O.; Valtchev, V.; Ordomsky, V. V.; Khodakov, A. Y., Direct dimethyl ether synthesis from syngas on copperzeolite hybrid catalysts with a wide range of zeolite particle sizes. Journal of Catalysis 2016, $338,227-238$.

31. Barbosa, F. S. R.; Ruiz, V. S. O.; Monteiro, J. L. F.; de Avillez, R. R.; Borges, L. E. P.; Appel, L. G., The Deactivation Modes of $\mathrm{Cu} / \mathrm{ZnO} / \mathrm{Al} 2 \mathrm{O} 3$ and HZSM-5 Physical Mixture in the One-Step DME Synthesis. Catalysis Letters 2008, 126 (1), 173-178.

32. Ordomsky, V. V.; Cai, M.; Sushkevich, V.; Moldovan, S.; Ersen, O.; Lancelot, C.; Valtchev, V.; Khodakov, A. Y., The role of external acid sites of ZSM-5 in deactivation of hybrid $\mathrm{CuZnAl} / \mathrm{ZSM}-5$ catalyst for direct dimethyl ether synthesis from syngas. Applied Catalysis A: General 2014, 486, 266-275.

33. Sierra, I.; Ereña, J.; Aguayo, A. T.; Arandes, J. M.; Olazar, M.; Bilbao, J., Co-feeding water to attenuate deactivation of the catalyst metallic function $(\mathrm{CuO}-\mathrm{ZnO}-\mathrm{Al} 2 \mathrm{O} 3)$ by coke in the direct synthesis of dimethyl ether. Applied Catalysis B: Environmental 2011, 106 (1), 167173.

34. Emeis, C. A., Determination of Integrated Molar Extinction Coefficients for Infrared Absorption Bands of Pyridine Adsorbed on Solid Acid Catalysts. Journal of Catalysis 1993, 141 (2), 347-354.

35. Kresse, G.; Hafner, J., Ab initio molecular dynamics for open-shell transition metals. Physical Review B 1993, 48 (17), 13115-13118.

36. Kresse, G.; Hafner, J., Ab initio molecular-dynamics simulation of the liquid-metal-amorphous-semiconductor transition in germanium. Physical Review B 1994, 49 (20), 1425114269.

37. Kresse, G.; Furthmüller, J., Efficient iterative schemes for ab initio total-energy calculations using a plane-wave basis set. Physical Review B 1996, 54 (16), 11169-11186.

38. Perdew, J. P.; Burke, K.; Ernzerhof, M., Generalized Gradient Approximation Made Simple. Physical Review Letters 1996, 77 (18), 3865-3868.

39. Blöchl, P. E., Projector augmented-wave method. Physical Review B 1994, 50 (24), 17953-17979.

40. Kresse, G.; Joubert, D., From ultrasoft pseudopotentials to the projector augmented-wave method. Physical Review B 1999, 59 (3), 1758-1775.

41. Pack, J. D.; Monkhorst, H. J., "Special points for Brillouin-zone integrations"---a reply. Physical Review B 1977, 16 (4), 1748-1749. 
42. Grimme, S.; Ehrlich, S.; Goerigk, L., Effect of the damping function in dispersion corrected density functional theory. 2011, 32 (7), 1456-1465.

43. Olson, D. H.; Kokotailo, G. T.; Lawton, S. L.; Meier, W. M., Crystal structure and structure-related properties of ZSM-5. The Journal of Physical Chemistry 1981, 85 (15), 22382243.

44. Matthias, T.; Katsumi, K.; Alexander, V. N.; James, P. O.; Francisco, R.-R.; Jean, R.; Kenneth, S. W. S., Physisorption of gases, with special reference to the evaluation of surface area and pore size distribution (IUPAC Technical Report). Pure and Applied Chemistry 2015, 87 (9-10), 1051-1069.

45. Palčić, A.; Ordomsky, V. V.; Qin, Z.; Georgieva, V.; Valtchev, V., Tuning Zeolite Properties for a Highly Efficient Synthesis of Propylene from Methanol. 2018, 24 (50), 1313613149.

46. Crépeau, G.; Montouillout, V.; Vimont, A.; Mariey, L.; Cseri, T.; Maugé, F., Nature, Structure and Strength of the Acidic Sites of Amorphous Silica Alumina: An IR and NMR Study. The Journal of Physical Chemistry B 2006, 110 (31), 15172-15185.

47. Primo, A.; Garcia, H., Zeolites as catalysts in oil refining. Chemical Society Reviews 2014, 43 (22), 7548-7561.

48. Dwyer, J.; Fitch, F. R.; Nkang, E. E., Dependence of zeolite properties on composition. Unifying concepts. The Journal of Physical Chemistry 1983, 87 (26), 5402-5404.

49. Liu, C.; Li, G.; Hensen, E. J. M.; Pidko, E. A., Relationship between acidity and catalytic reactivity of faujasite zeolite: A periodic DFT study. Journal of Catalysis 2016, 344, $570-577$.

50. Shen, W.-J.; Jun, K.-W.; Choi, H.-S.; Lee, K.-W., Thermodynamic investigation of methanol and dimethyl ether synthesis from CO2 Hydrogenation. Korean Journal of Chemical Engineering 2000, 17 (2), 210-216.

51. Montesano, R.; Narvaez, A.; Chadwick, D., Shape-selectivity effects in syngas-todimethyl ether conversion over $\mathrm{Cu} / \mathrm{ZnO} / \mathrm{Al} 2 \mathrm{O} 3$ and zeolite mixtures: Carbon deposition and byproduct formation. Applied Catalysis A: General 2014, 482, 69-77.

52. Ciftci, A.; Varisli, D.; Cem Tokay, K.; Aslı Sezgi, N.; Dogu, T., Dimethyl ether, diethyl ether \& ethylene from alcohols over tungstophosphoric acid based mesoporous catalysts. Chemical Engineering Journal 2012, 207-208, 85-93. 